\title{
Being a peer mentor for a person recovering from an acute myocardial infarction
}

\author{
Lena Junehag ${ }^{* 1}$, Jacek Hochwälder ${ }^{2}$, Marianne Svedlund ${ }^{1}$ \\ ${ }^{1}$ Department of Nursing Science, Mid Sweden University, Östersund, Sweden \\ ${ }^{2}$ Division of Psychology, School of Health, Care and Social Welfare, Eskilstuna, Sweden
}

Received: June 18, 2015

Accepted: December 16, 2015 Online Published: January 7, 2016

DOI: $10.5430 /$ jnep.v6n5p41

URL: http://dx.doi.org/10.5430/jnep.v6n5p41

\begin{abstract}
Challenges after an acute myocardial infarction (AMI) is to manage the disease and to prevent a second AMI. Other people with the same illness have a unique understanding of the situation; therefore, they can provide valuable support. Being a peer mentor and contributing one's own experiences of the same illness can even lead to increased self-confidence. The aim was to describe personal perceptions of being a peer mentor for a person recovering from an AMI. Patients in three sparsely populated counties, who had experienced their first AMI the previous year, were offered contact with peer mentors. The peer mentors had experienced an AMI between one and ten years ago. Sixteen of them were interviewed after one year as mentor. The interview texts were analysed using qualitative content analysis. Two themes summarized the interview results, "being in charge" and "being comfortable", which incorporated six subthemes. The peer mentors also answered a questionnaire, and according to the purpose of the study, certain parts of the questionnaires were analysed using a paired-sample $t$-test. The dimensions measured in the Revised Illness Perception Questionnaire (IPQ-R) showed significant increased mean values, including Illness Coherence ( $p$ $\leq .001)$ and Emotional representation $(p \leq .05)$. Highlights of the results included that being a peer mentor led to feelings of pride and that peer mentors should be preceded by a careful matching between patients and mentors.
\end{abstract}

Key Words: Intervention, Mentoring, Rural areas, Support

\section{INTRODUCTION}

The number of deaths in Sweden due to an acute myocardial infarction (AMI) has decreased drastically since 1995, due to continuous developed medical care and faster prehospital treatment. ${ }^{[1]}$ However, for many patients the AMI is a disruption in life, and a reminder that life is fragile and uncertain. ${ }^{[2]}$ Recovering from AMI is a process of learning to live with and to manage fear and insecurity, which place great demands on care planning at discharge. ${ }^{[3]}$ Many patients struggle to feel safe after their AMI due to difficulties to handle their insecurity and to manage their disease. ${ }^{[4,5]}$
Informal contacts between fellow patients are a way for them to find someone who has a genuine understanding of their condition and who may provide valuable support after an AMI. ${ }^{[4]}$ One year after their AMI, one group of persons with peer mentors indicated that they appreciated the mentors' supportive roles. ${ }^{[5]}$ Therefore, it is of interest to find out whether such a relationship also may be of importance for mentors, so the aim was to describe personal perceptions of being a peer mentor for a person recovering from an AMI. The following issues were explored: How did they experience their commitment after one year of mentoring others? Did their own illness perception or emotional state change? Sweden.

*Correspondence: Lena Junehag; Email: lena.junehag@miun.se; Address: Department of Nursing Science, Mid Sweden University, Östersund, 
An evaluation of the group education directed at patients, experienced peers, relatives and healthcare professionals showed that patients appreciated listening to experienced peers, which had given them hope. Furthermore, the peer mentors felt a sense of satisfaction by sharing their experiences; the mentors themselves had needed, but not experienced, a similar mentoring program. Both the afflicted persons and their relatives felt that only peers could really understand their experiences. ${ }^{[6]}$ This finding is similar to the results of another study indicating that AMI sufferers involved in good working peer mentoring relationships. The mentors had shared their experiences and in that way helped them develop valuable insights into their AMI experiences. ${ }^{[7]}$ Sharing experiences with peers leads to feelings of being normal and having normal behaviours because the peer's own experiences are unique and differ from the experiences of professionals. ${ }^{[8]}$ In a mixed study of individuals undergoing post-AMI rehabilitation, an intervention group was offered to lay tutors. The results from both groups showed significant differences in self-efficacy for both the disease and symptoms but not for expected changes at a four-month follow-up. However, the intervention group tended to have decreased levels of anxiety, self-efficacy for disease, depression and cognitive symptom management. ${ }^{[9]}$

Peer mentoring is different from conventional mentoring in that peer mentoring confirms the individuals' experiences as being valuable. The mentor builds a "development relationship" with one or more persons, and even if the purpose is not to become friends, friendship is a common outcome. ${ }^{[10]}$ Bozeman and Feeney ${ }^{[11]}$ developed a mentoring model in which the meaning of mentorship is informal and described as a "dyadic relationship" (Idem). Mentors diagnosed with heart failure were recruited to participate in an educational session and then act as peer support to fellow patients; the mentor's self-confidence and self-care increased during their engagement. ${ }^{[12]}$ However, informal contact between fellow patients after an AMI has been rarely studied. ${ }^{[4]}$

People living long distances from hospitals may have difficulty participating in rehabilitation programmes or support groups. Therefore, alternatives for support may be needed during their recovery. People who have the same disease and have accepted their illness would be excellent role models with valuable experiences for people who are newly diagnosed with an AMI.

\section{MethodS}

\subsection{Design and subjects}

This study is part of a longitudinal project that includes an intervention. To meet the study aim, both questionnaires and interviews were used. ${ }^{[13]}$ Complementary methods, rather than the use of a single method, allow broader insights into a problem because the methods complement each other. ${ }^{[14]}$ Data collection was conducted from September 2010 to October 2013. The results from the questionnaires should be seen as complementary to the interviews.

The intervention consisted of offering a newly, first-time afflicted person, contact with a peer mentor during their recovery. They all lived in sparsely-populated areas, and reason to choose that context was because it sometimes are difficulties taking part of rehabilitation programmes due to long distances to hospitals. To be included, the peer mentors had to have experienced an AMI one to ten years before committing to the study and be $<75$ years old. Both men and women were recruited for voluntary participation by answering advertisements or after having received information at local heart-lung associations. In total, 52 people were interested in acting as peer mentors, and most of them lived countryside. Those who were eligible to be a peer mentor $(n=34)$ were not provided with any preparation prior to their interaction; they were asked to draw on their own experiences with an AMI by being a peer mentor for the newly diagnosed person during their recovery. The peer mentor and mentee participated in the project over the course of one year, i.e., the mentee's first year post-AMI.

\subsection{Procedure and settings}

The mentors and mentees lived in three counties composed of large, rural areas in the middle of Sweden. To allow for the best possible matching, the mentor and mentee were matched by age and gender and preferably lived in the same location. The mentees were recruited by their coronary care nurses during their first follow-up visit, approximately two weeks after discharge from the hospital; they were selected consecutively to be offered a mentor, or not. If they agreed to participate, a suitable peer mentor was selected, and they were informed that a potential mentee was interested in being contacted. Both the mentor and the mentee then answered a questionnaire, and when the first author received their questionnaire responses, the mentor was given access to the mentees' name and phone number. The peer mentors did not have any special training for their engagement, and they were responsible for making contact with their mentee. The mentors had open contact with the authors, and they were also contacted at least once (after four months) by the authors.

The regional ethical committee at Umeå University provided permission (09-100 M) for the project, which conformed to the principles outlined in the Declaration of Helsinki, 1964. All mentors received verbal and written information stating 
that their participation was voluntary and that they had the right to withdraw whenever they wanted without any explanation. The mentors were informed about confidentiality and were assured that individual participants would not be identifiable in the reports.

\subsection{Data collection}

After the project ended, a letter was sent to all of the peer mentors to ask them to participate in a telephone interview. Soon after they had received the letter 16 of them reported interest in participating, and those were contacted to decide time for the interview. No reminders were sent to those who not responded, because the interview material was judged to be sufficient. The first author conducted the interviews using questions that focused on the participant's perceptions of being a peer mentor to someone experiencing their first AMI. The interviews were digitally recorded, which had been previously described in the letter. The interviews were semistructured, and a guide was used based on a few areas, ${ }^{[13]}$ including the following examples: "What has being a mentor meant to you?" and "How should a mentor be prepared?". Clarifying questions included the following options: "Could you provide an example?" or "What do you mean?". The interviews were conducted one to two years after the peer mentoring was completed.

The peer mentors answered a baseline questionnaire before they had access to the mentee's name and phone number and answered a second questionnaire one year later. In this study a certain part of the survey data were used to complement the results from the interviews, i.e., those parts that include perception of illness and emotional changes which possibly could confirm the contents from the interviews. The focus of the survey was to investigate whether any changes occurred over time by using a questionnaire that measured illness perception through the Revised Illness Perception Questionnaire (IPQ-R) and Health Related Qualitative of Life (HRQoL) through the Short Form 36 (SF-36) Health Survey. The peer mentors were also asked questions about demographics and their commitment.

\subsection{Measures}

The object of the IPQ-R is to help respondents quantify their own perceptions of their illness. ${ }^{[15]}$ The questionnaire is divided into three sections. 1) The Identity scale consists of 14 symptoms, as follows: "those symptoms have occurred after the illness" or "those symptoms are related to the illness" followed by two columns answered with "yes" or "no" (more "yes" responses in the second column indicate that more symptoms are related to the illness). 2) Perception of illness is measured by 38 items answered using a five-point Lik-

Published by Sciedu Press ert scale. Several items were reversed before analysis. The items are then grouped into 7 dimensions; the present study focuses on Illness coherence (5 items) and Emotional representations (6 items). Those dimensions address the extent to which an individual is aware of one's illness and imagination based on feelings. High scores indicate having insight and, consequently, represent positive beliefs. 3) Cause of illness consists of 18 items but is not presented. The Swedish translated version of the IPQ-R was used. ${ }^{[16]}$ The Cronbach's $\alpha$ coefficient achieved for the dimensions used in the study were .670 and .779 at baseline for Illness Coherence and Emotional Representation, respectively and .931 and .779 at the second time point for Illness Coherence and Emotional Representation, respectively.

The SF-36 measures HRQoL and is appropriate for studying changes over time. The questionnaire is comprised of 35 items grouped into 8 multi-item scales that measure function and well-being. The Functional scales (physical function) include Role function-Physical causes (4 items), Role functionEmotional causes ( 3 items), Social Function ( 2 items) and Bodily Pain ( 2 items). The Well-being scales are Mental Health (5 items), Vitality (4 items) and General Health (5 items). One question addresses changes in health compared with one year earlier. The items are scored from 1-2, 1-3, 1-5 and 1-6, and some questions must be transformed to a $0-100$ scale, allowing the answers to consist of corresponding levels. The scales are also developed to summarise two health indexes/overall dimensions, as follows: Physical Component Score (PCS) and Emotional representation, such as the Mental Component Score (MCS). ${ }^{[17]}$ The average PCS and MCS scores facilitate the interpretation of how an illness affects functioning in that higher scores indicate better functioning. At baseline, the Cronbach's $\alpha$ coefficient achieved the following measures: PCS $=.661, \mathrm{MCS}=.752$. After one year as a mentor, the PCS $=.772$ and $\mathrm{MCS}=.827$.

\subsection{Analysis}

The interviews were transcribed verbatim soon after their implementation. Qualitative content analysis was used to analyse the interviews. Thus, analysis was used to reduce the amount of text with the purpose of identifying consistency. ${ }^{[13]}$ According to description of the analysis, the analysis process was carefully performed to ensure consistency with the text and was then conducted step-by-step. After transcription, the interviews were read several times to learn the content. After this step, meaning-units were constructed, and depending on the content, they consisted of one or more sentences. The next step was to organise the units according to their contents, and condense them to a shorter form, label with a code, and then sort into subthemes based on 
similarities. In this analytical process, each step results in a higher abstraction level. The results are a summary from the content of the interviews; a synthesis process formulated the final results, culminating in 6 subthemes and 2 themes. The dialectic process described above is not a linear; the process moves back-and-forth between the whole and the different parts. The analysis was performed by the first author in consultation with the co-authors until an agreement was reached.

Survey data were analysed using SPSS (SPSS 20.0 statistics, IBM, New York, US). Descriptive data are presented in frequencies. The decision was to analyse the dimensions that could be related to the results of the interviews. The dimensions in IPQ-R; Illness coherence and Emotional representations were analysed using a paired-sample $t$-test. This analysis was performed to determine if the mentors' answers had changed after one year of mentoring. A paired-sample $t$-test was also used to evaluate if the PCS and MCS results of the SF-36 had changed during mentoring. In both questionnaires, a level of $p<.05$ was considered to be statistically significant.

\section{RESULTS}

There were 52 people interested in being a mentor; 34 of them became peer mentors. The number who became peer mentors depended on the number of newly diagnosed persons with AMI who were sorted into the group newly afflicted "with peer mentors". Because the baseline measures and the measures at study completion were compared, only those who answered both questionnaires were included in the survey $(n=22), 16$ of them were men and six were women. Mean age for all 22 participants was $64.36(\mathrm{MD}=65.00)$, 18 were married and four single, i.e., lived alone. Most were retired $(n=17)$, one was unemployed and four employed. There was a mix of their educational levels; Compulsory school $(\mathrm{n}=7)$, Upper secondary school $(\mathrm{n}=8)$ and University $(n=7)$. The number who participated in interviews were $16 ; 12$ of them were men and four women.

\subsection{The interviews}

The analysis resulted in 2 themes and 6 subthemes. The first theme, Being in charge, consisted of the following subthemes: "Fitting each other", "Lacking personal chemistry", and "Experiencing obstacles to success in the task". The second theme, "Being comfortable", consisted of the following subthemes: "Gaining a deeper insight into what an AMI implies", "Having a humble attitude" and "Growing with the task". The subthemes are illustrated with quotations and marked with gender and age.

\subsection{Being in charge}

\subsubsection{Fitting each other}

The relationships between the mentor and the mentee were mostly described as easy-going when the mentees had a positive attitude and the pairs had personal chemistry: "There were no 'twists and turns' in getting to know each other (...) after our first meeting, we understood that we had the same "view on life"" (male, 62). Being a peer mentor was described as a fun and a positive experience: "I feel that this has been good, and I think that the other person also had this opinion, and I have even been happier" (male, 70). In some cases, participants made a new friend; those pairs had common interests and, for example, visited each other in their homes or took long walks together in the forest. Others devoted time at the local heart and lung association together, contributing to increased social interaction for the mentees.

\subsubsection{Lacking personal chemistry}

The mentors with a mentee with whom the relationship did not work attributed the conflict to having different personalities; therefore, the match was unsuccessful. "Together, we were a wrong combination; there was no personal chemistry" (male, 55). Some mentors mentioned that a requirement for the mentorship should be good personal chemistry and having similar life situations. According to the mentors, one solution to appropriate matching could be to make an inventory of interests among those participating in a mentoring program. Other mentors questioned the gender-specific nature of the mentorship because some men would be more frank with women.

\subsubsection{Experiencing obstacles to success in the task}

All peer mentors began their mentorship by calling their mentee on the telephone, which generated feelings of excitement. There were mentors who mostly, or even only, had contact with their mentee by telephone. One mentor said "I let her steer and decide how it should be" (female, 69). Another pair reported only making contact through the initial phone call, while most pairs booked meetings or had further spontaneous contact. Those mentors engaging in only a few contacts with the mentees indicated that the interaction had felt "wrong" from the beginning. One mentor wished that they could have begun again with personal meetings. Another mentor thought he had been too active: "I should have been more careful because I think I was too indiscreet at the beginning" (male, 62). Some mentees were perceived as uninterested or difficult to make contact with, and their mentors expressed disappointment in those cases. In some cases, the mentor perceived that the mentee had no need for this type of support, making the mentor feel unwanted, as follows: "Perhaps he felt that I was the wrong guy" (male, 55). 
One mentor blamed an unsuccessful relationship on long distances. One of the respondents felt that the mentorship was meaningless because the mentor had suggested meetings but the mentee had declined. One mentor said "I don't think that I'm the right person for this" (female, 60).

\subsection{Being comfortable}

\subsubsection{Gaining a deeper insight into what an AMI implies}

The peer mentors felt that AMI often resulted in brooding by those who are afflicted, leading to feelings of loneliness. According to the mentors, it is important to divert such ponderings after an AMI. In their own recovery, a majority of them had experienced a lack of support by someone who understood their situation: "The idea that one's experience could pep up someone who newly has done this journey (...) the idea with this thing is really good" (male, 55). By acting as a peer mentor, the participants had developed new, valuable knowledge about how different people could be. They had developed a deeper insight regarding the individuality and differences between people's consequences and reactions after an AMI. They asserted that there is a need for peer support in general after an AMI, particularly for men.

\subsubsection{Having a humble attitude}

According to the mentors, rapid contact and personal meetings are important determinants of how the relationship will continue. Being a peer mentor requires respect for the task by knowing one's own limitations, being humble and having a keen ear and insight. A majority of the mentors lacked any preparation before their commitment, e.g., meetings with other mentors could have been valuable. They would have appreciated the opportunity to discuss and receive help with arrangements before and during their commitment. Some peer mentors had been supportive earlier in other situations and felt comfortable with the situation. Others felt that even if being a peer mentor was a new situation, they trusted in their own experience, felt secure with that experience and acted in the way they thought was best. Most of them were satisfied with the way the project was carried out and felt that access to the authors was sufficient if they had questions: "This arrangement is not foreign to me" (male, 54).

\subsubsection{Growing with the task}

Acting as a peer mentor mattered to them and was something positive; sharing their experiences with their mentee had given them good feelings. However, AMI had become a secondary subject of conversation, and the mentorship had developed into a mutual relationship, as follows: "I related what I had gone through, and he went through much the same thing" (male, 48). It was interesting to discover that mentors and their mentees had the same view on life, something a

Published by Sciedu Press majority of the mentors discovered. Some of them revealed that their mentees had increased feelings of safety thanks to the relationship; "He has got more positive thoughts (...) because in the beginning he was negative, but I have helped him change his mind and in the final phase, he was much happier" (male, 62). The mentors expressed that they even developed a new view of life and noted that their participation had contributed to a feeling of being confirmed. It felt good to be "useful" by sharing their experiences with another person, which culminated in feelings of pride. One mentor even found that being a mentor had been self-healing, as follows: "This has developed an inversion for me, I have simply become more positive in my life than earlier" (male, 62).

Most mentors would like to continue mentoring because they learned something new and would like to try again. Some of them could even imagine being a mentor for more than one person. Other mentors would like to be a mentor in another way or to be placed with "the right person". They supported mentorship as a way to provide this type of peer support for patients with a newly diagnosed AMI: "I'm one of them who thinks that this is important, I really do" (female, 69).

\subsubsection{The survey component}

Descriptive results from the IPQ-R showed that the following symptoms were related most frequently to the illness: impaired physical ability $(\mathrm{n}=12 ; 54.5 \%)$, shortness of breath $(\mathrm{n}=11 ; 50 \%)$ and fatigue $(\mathrm{n}=11 ; 50 \%)$. The paired-sample $t$-test analysis of the Illness Coherence and Emotional Representation in the IPQ-R showed a statistically significant increase in both dimensions from baseline to the second measure after one year. According to the IPQ-R, there was a higher level of insight regarding the illness after one year than at baseline. The Eta Squared $\left(\eta^{2}\right)$ statistic indicated a large effect size in both of the following dimensions: Illness Coherence $\eta^{2}=0.49$ and Emotional Representation $\eta^{2}=$ 0.18. The PCS and MCS (in SF-36) were analysed to assess whether the summarised answers changed during the mentors' commitment. The mean values decreased from baseline to the second measurement; however, the paired-samples $t$-tests did not demonstrate any significant $p$-values in the SF-36 for PCS or MCS (see Table 1).

Of the 22 peer mentors, 16 noted that the mentorship had been "fun, momentous, valuable or instructive", while four noted that it had been "difficult or meaningless". Two mentors did not note anything. Eleven (50\%) would have continued contact with their mentee after the project had ended, and $13(59 \%)$ would become a mentor if they were asked again. 


\section{Discussion}

The main results of this study were that peer mentoring was an interesting and valuable experience, sometimes with its own benefits. Furthermore, the mentors reduced their own AMI symptoms, and their Illness Coherence and Emotional representation increased at statistically significant levels during their engagement. However, some mentors did not find the mentoring work satisfying, mostly because of a lack of interaction with their mentee. Most peer mentors had an upper secondary school and university education level. That is notable because the education level is generally low in the three counties, especially outside of densely built-up areas. It would be interesting to know whether education influenced the mentors' choice to act as a peer mentor. However, it is not possible to draw any conclusions of that, and furthermore most mentors were retired at the time of their engagement.

Table 1. Paired-sample $t$-test with values from two measured dimensions in IPQ-R, and the over-all dimensions in SF-36

\begin{tabular}{|c|c|c|c|c|c|c|c|}
\hline & $\begin{array}{l}\text { Baseline } \\
\text { Mean (SD) }\end{array}$ & $\begin{array}{l}\text { One year } \\
\text { Mean (SD) }\end{array}$ & $\begin{array}{l}\text { Mean } \\
\text { difference }\end{array}$ & $t$ & $d f$ & $p$ & $\eta^{2}$ \\
\hline Illness Coherence & $2.31(0.69)$ & $3.83(0.97)$ & -1.52 & -4.52 & 21 & $<.001 * * *$ & 0.49 \\
\hline Emotional representation & $2.36(0.65)$ & $2.71(0.65)$ & -.35 & -2.15 & 21 & $<.05^{*}$ & 0.18 \\
\hline PCS & $56.91(10.92)$ & $55.27(11.90)$ & 1.63 & 0.96 & 21 & & \\
\hline MCS & $61.20(11.30)$ & $58.93(13.63)$ & 2.28 & 1.1 & 21 & & \\
\hline
\end{tabular}

Note. $\mathrm{SD}=$ standard deviation; ${ }^{* * *} p<.001 ; * p<.05 ; \eta^{2}=$ Eta Squared.

The results showed that the participants were uncomfortable before the first phone-call to their mentee. Sometimes the relationship was unsuccessful because there was no continuation. Without drawing conclusions as to why, those mentors had not met their mentee personally. Well-working mentoring relationships were characterised by a good relationship, which is not surprising because the only tool for their support was themselves. According to Holbeche, ${ }^{[10]}$ peer mentoring differs from other models. Presumably, the initial telephone call revealed differences in personalities and a lack of common interests. Others who continued with regular contact by phone missed opportunities to meet the other person. In some cases, this lack of meeting could be blamed on long distances because the intention that they should live in the same locality was sometimes difficult to fulfil in sparsely-populated areas.

In the results, the participants expressed dissatisfaction with the matching. The importance of matching was shared by the participants in a study ${ }^{[18]}$ on peer-mentored patients with arthritis. Their participants expressed that personality, interests, gender and other similarities were essential prerequisites for a successful mentorship. In some cases, the results in the present study show introspection for having been too active from the beginning. This activity may have been scary for the mentee because studies have confirmed that immediately after an AMI, most patients view their illness as acute and not chronic. ${ }^{[19,20]}$

More of the mentors also mentioned that they had missed support during their own recovery, something that was also observed in a study by. ${ }^{[6]}$ Presumably, this was a reason for some mentors to announce their interest to participate in our project. To survive a serious disease and to be aware that no one could replace their own experiences seems to be valuable and contributes to pride, as shown by Arndt et al. ${ }^{[8]}$ Furthermore, receiving support could be a decisive element regarding how a person affected by an AMI manages the illness. ${ }^{[21]}$ Notably, even though the mentors were aware of their AMI and possible consequences, they developed a deeper insight about the illness. This insight could result from being an object and not a subject, thus providing an understanding without emotional commitment. One interesting finding was that some participants would have liked to be a mentor for the opposite gender. However, this result differs from other results. ${ }^{[4]}$

More of the mentors in the present study lacked some type of education for the task and disclosed their honest commitment to being a peer mentor. This observation is consistent with the review by Embuldeniya et al. ${ }^{[22]}$ which noted the mentors' willingness to share experiences of living with their disease and their missed opportunity to obtain more knowledge about the disease. Unfortunately, this type of knowledge was impossible to offer due to the prevailing circumstances. Furthermore, the results showed that most of the mentors had positive feelings regarding the use of their own experiences. For most of them, being a peer mentor had resulted in a valuable friendship and a new awareness. According to those results, their increased levels of Illness Coherence and Emotional Representation could be interpreted as providing a greater understanding of their illness perception at the second measurement. There are similarities with another study ${ }^{[23]}$ regarding mentorship, but in that study, the researchers ed- 
ucated the mentors. Furthermore, their mentors could be a mentor for more than one mentee, who were followed for only three months. That configuration differs from our study because we allowed the mentors to act as lay people, and they had contact with only one mentee for a duration of one year.

\section{Discussion of methods}

Our method of conducting the intervention assumed that people with same experiences are a valuable support for people with an illness or in other special circumstances. For example, long distances prevent some people from taking part in self-help groups offered by health care. One limitation in the present study is the small number of participants. Only 22 peer mentors $(65 \%)$ answered questionnaires in both occasions, which is a too small of sample to draw conclusions; therefore, the survey component only shows tendencies. However, the combination of methods could be observed as a strength, and 16 peer mentors were interviewed which is an enough to reach trustworthiness for the interview part of the study, because it was abundant content in the interviews.

The way that we investigated the perception of being a peer mentor has rarely occurred; studies addressing mutual aid/peer support (during Cardiac Rehabilitation) are mostly based on focus groups, such as the study by Arndt et al. ${ }^{[8]}$ However, for our study, the peer mentors were the intervention personified and, therefore, were the reason for conducting the interviews. Conducting the interviews was necessary for the present study, but there was no way to perform the interviews except by phone. This method is a good option when there are long distances. In a review article ${ }^{[23]}$ it was noted that when telephone interviews have been employed, respondents have been described as relaxed and willing to share their stories. However, further research is needed in this area.

Content analysis is appropriate for studies with a qualitative descriptive design, and such analysis is systematic and therefore replicable. The careful analysis of the interview texts ensures dependability. ${ }^{[13]}$ According to the interview results, our choice to investigate the peer mentor's Illness Coherence and Emotional Representation in addition to PCS and MCS was based the interest in understanding whether their mentoring affected their perception of their own AMI. The desire to examine changes that occurred over time motivated the use of a pair-sampled $t$-test, which is useful when the same individuals are evaluated at two different time points. ${ }^{\text {[24] }}$

According to a review of five studies using a mixed design, the authors ${ }^{[14]}$ reported the importance of having a good accountable rationale with a reasonable account. One study ${ }^{[25]}$ indicated that using a mixed method in this type of study is suitable because it enabled the findings reach a deeper dimension. The authors described challenges when using triangulation as a research method. Their qualitative data had provided a deeper understanding of the quantitative data, indicating that the results from the two methods were complementary. The small sample in this study could be seen as limiting, and if focus was to receive quantitative results, it would not have been enough. However, the quantitative part was used as a complement to the interviews, and there are no rules about sample size in qualitative research. In this study we estimated 16 peer mentors to be an adequate number of participants to create understanding of the phenomenon.

\section{Conclusions}

A majority of the participants reported that they lacked contact with other persons with an AMI during their own recovery. Organised peer mentoring models could be offered as a complement to existing rehabilitation programmes for those who need this type of support. This type of peer mentoring should be preceded by education suitable for this commitment, and matching should be conducted. Being a peer mentor allows the sharing of one's own experiences with others. This sharing may lead to a feeling of being valuable and, therefore, the relationship results in a win-win situation.

\section{ACKNOWLedgements}

Thanks to all participants who sharing their valuable perceptions.

\section{CONFLicts OF INTEREST Disclosure}

The authors declare that there is no conflict of interest.

\section{REFERENCES}

[1] Socialstyrelsen. Myocardial infarctions in Sweden 1988-2012 - Official Statistics of Sweden. 2013.

[2] Kristofferzon ML, Löfmark F, Carlsson M. Striving for balance in daily life: experiences of Swedish women and men shortly after a myocardial infarction. Journal of Clinical Nursing. 2007; 16: 391-
401. PMid:17239075 http://dx.doi.org/10.1111/j.1365-2 $702.2005 .01518 . x$

[3] Tod A. Exploring the meaning of recovery following myocardial infarction. Nursing Standard. 2008; 23: 35-42. PMid:18837278 http://dx.doi.org/10.7748/ns2008.09.23.3.35.c6672

[4] Steen Isaksen AS, Gjengedal E. Significance of fellow patients for 
patients with myocardial infaction. Scandinavian Journal of Caring Science. 2006; 20: 403-411. PMid:17116149 http://dx.doi .org /10.1111/j.1471-6712.2006.00421.x

[5] Junehag L, Asplund K, Svedlund M. Perceptions of illness, lifestyle and support after an acute myocardial infarction. Scandinavian Journal of Caring Science. 2014. PMid:23763508 http://dx.doi .org $/ 10.1111 /$ scs. 12058

[6] Ivarsson B, Klefsgård R, Nilsson G. Experiences of group education - A qualitative study from the viewpoint of patients and peers, next of kin and healthcare professionals. Nordic Journal of Nursing Research \& Clinical Studies. 2011; 31(1): 35-39. http: //dx.doi.org/10.1177/010740831103100207

[7] Junehag L, Asplund K, Svedlund M. A qualitative study: Perceptions of the psychosocial consequences and access to support after an acute myocardial infarction. Intensive and Critical Care Nursing. 2014; 30: 22-30. PMid:23958430 http://dx.doi.org/10.1016/j.iccn. 2013.07.002

[8] Arndt M, Murchie F, Schembri AM, et al. "Others Had Similar Problems and You Were Not Alone" - Evaluation of an OpenGroup Mutual Aid Model in Cardiac Rehabilitation. Journal of Cardiovascular Nursing. 2009; 24: 328-335. PMid:21206355 http: //dx.doi.org/10.1097/JCN.0b013e3181a1c236

[9] Barlow JH, Turner AP, Gilchrist M. A randomised controlled trial of lay-led self-management for Myocardial Infarction patients who have completed cardiac rehabilitation. European Journal of Cardiovascular Nursing. 2009; 8: 293-391. PMid:19261545 http: //dx.doi.org/10.1016/j.ejcnurse.2009.02.002

[10] Holbeche L. Peer mentoring: the challenges and opportunities. Career Development International. 1996; 1(7): 24-27. http://dx . doi .org/10.1108/13620439610152115

[11] Bozeman B, Feeney MK. Mentor matching - a "Goodness of Fit" Model. Administration and Society. 2008; 40: 465-482. http: //dx.doi.org/10.1177/0095399708320184

[12] Riegel B, Carlson B. Is Individual Peer Support a Promising Intervention for Persons With Heart Failure? Journal of Cardiovascular Nursing. 2004; 19(3): 174-183. PMid:15191260 http: //dx.doi.org/10.1097/00005082-200405000-00006

[13] Patton MQ. Qualitative Research \& Evaluation Methods (3rd ed.). London: Sage Publications, Inc. 2002.

[14] Creswell JW, Fetters MD, Ivankova NV. Designing a Mixed Methods Study In Primary Care. Annals of Family Medicine. 2004; 2(1): 7-12. http://dx.doi.org/10.1370/afm.104
[15] Moss-Morris R, Weinman J, Petrie KJ, et al. The Revised Illness Perception Questionnaire (IPQ-R). Psychology and Health. 2002; 17(1): 1-16. http://dx.doi.org/10.1080/08870440290001494

[16] Alsén P, Brink E, Persson LO, et al. Illness Perception after Myocardial Infarction: Relations to Fatigue, Emotional Distress, and Health-Related Quality of Life. Journal of Cardiovascular Nursing. 2010; 25(2): E1-E10. PMid:20168186 http://dx.doi.org/10. $1097 /$ JCN . Ob013e3181c6dcfd

[17] Sullivan M, Karlsson J, Taft C. Health survey: Swedish Manual and Interpretation Guide - in Swedish (2 edn ed.). Gothenbourg: Sahlgrenska University Hospital. 2002.

[18] Sandhu S, Veinot P, Embuldeniya G, et al. Peer-to-peer mentoring for individuals with early inflammatory arthritis: feasibility pilot. Brittish Medical Journal - Open. 2014; 3: 1-9.

[19] Wiles R, Kinmonth AL. Patients' understandings of heart attack: implications for prevention of recurrence. Patient Education and Counseling. 2001; 44: 161-169. http://dx.doi.org/10.1016/S 0738-3991 (00) 00187-7

[20] Brink E, Karlson BW, Hallberg LRM. Readjustment 5 months after a first-time myocardial infarction: reorienting the active self. Journal of Advanced Nursing. 2006; 53(4): 403-411. PMid:16448483 http://dx.doi.org/10.1111/j.1365-2648.2006.03737.x

[21] Mierzyńska A, Kowalska M, Stepnowska M, et al. Psychological support for patients following myocardial infarction. Cardiology Journal 2010; 17: 319-324. PMid:20535728

[22] Embuldeniya G, Veinot P, Bell E, et al. The experiences and impact of chronic disease peer support interventions: A qualitative synthesis Patient Education and Counseling. 2013; 92: 3-12. PMid:23453850 http://dx.doi.org/10.1016/j.pec.2013.02.002

[23] Novick G. Is There a bias Against Telephone Interviews in Qualitative Research? Research in Nursing and Health. 2008; 31: 391-398. PMid:18203128 http://dx.doi.org/10.1002/nur. 20259

[24] Djurfeldt G, Larsson R, Stjärnhagen O. Statistical toolbox - social cause analysis with quantitative methods.(Swe. Statistisk verktygslåda - samhällsvetenskapliga orsaksanalys med kvantitativa metoder). Lund: Studentlitteratur AB. 2003.

[25] Bekhet A, Zauszniewski J. Methodological triangulation: an approach to understanding data. Nurse Researcher. 2012; 20(2): 40-43. PMid:23316537 http://dx.doi.org/10.7748/nr2012.11.20. 2.40. c 9442 